\title{
Impact of the Exposure to Entrepreneurship Education on Students' Entrepreneurial Intentions: A Case - Based Study of the Higher Education in Brazil
}

\author{
Hong Yuh Ching ${ }^{1}$, José Renato Kitahara ${ }^{1}$ \\ ${ }^{1}$ Centro Universitário FEI, São Bernardo do Campo, Brazil \\ Correspondence: Hong Yuh Ching, Centro Universitário FEI, São Bernardo do Campo, Brazil.
}

Received: November 8, 2017

Accepted: November 23, 2017

Online Published: November 28, 2017

doi:10.11114/bms.v3i4.2772

URL: https://doi.org/10.11114/bms.v3i4.2772

\begin{abstract}
The objective of this paper is to examine the impact of the exposure to entrepreneurship education on students' entrepreneurial intentions. This is an exploratory quantitative study. A questionnaire based on McClelland model was applied on a sample of 230 Business undergraduate students of a Brazilian university throughout a period of eight semesters. The following statistical tools were used - t-Student, ANOVA, Hierarchical Cluster, K-Means Cluster, Cross tabulation and Chi-Square. No differences were significant to discriminate gender, nor previous experiences on family business. Yet, there were no significant changes of entrepreneurial competencies factors mean values when considering longitudinal behavior in units of semesters in the period of 2014 to 2017. Although there are two groups representing different levels of intention to undertake, even the group with less intention presents mean value around and/or above the minimum threshold value (as 30) mentioned by McClelland. The results of all tests provide empirical evidences that allow confirming that the exposure to entrepreneurial education indeed influences and positively the students' entrepreneurial intentions. The entrepreneurial education may not be only related to development of entrepreneurs or tied to the specifics of starting a business. It should also contribute to economic development, enterprising spirit and work skills among people aiming professional self-realization in various contexts. Two directions for policy intervention in the area of the higher education in Brazil are offered: entrepreneurship becomes an interdisciplinary program and be present in all courses and bring universities closer to the market by strengthening the entrepreneur ecosystem.
\end{abstract}

Keywords: entrepreneurship education, entrepreneurial intention, McClelland model, higher education, entrepreneurship

\section{Introduction}

Entrepreneurship has been considered as a factor for widening career options and determining the individual professional development. Between $70 \%$ and $80 \%$ of Brazilian population agree that start a business is a desirable career option and value the entrepreneur's success. Yet, having its own business is among their main dreams for $34 \%$ of them in 2015 compared to $31 \%$ in 2014 (GEM, 2015). A recent study from Endeavor and Sebrae (2017) showed that among the university students in Brazil, 5,7\% of them are already entrepreneurs, $21 \%$ think in starting a business in the future and $73,3 \%$ have no intention in being an entrepreneur.

The results presented in the European Commission study (2012) show clearly that entrepreneurship education makes a difference. Those who went through entrepreneurial and activities, display more entrepreneurial attitudes and intentions, get a job earlier after finishing their studies, can innovate more even as employees in a firm, and start more companies.

However, education and training were considered as limiting conditions to entrepreneurship activity in Brazil for $49 \%$ of the experts heard in the GEM study (2015). Despite this scenario, a survey conducted in 2014 among 4911 students of 70 Brazilian higher education institutions, regarding the teaching of entrepreneurship, showed that only $48,7 \%$ of them took a course related to entrepreneurship, 11,1\% have no interest and 17,6\% said that their institution do not offer any related discipline (Endeavor \& Sebrae, 2015). In another study with 135 Brazilian business courses in 2010, 71\% of them offered a specific or related discipline in entrepreneurship (Vieira, Melatti, Oguido, Pelisson, \& de Negreiros, 2013). Entrepreneurial programs offer students the tools to think creatively, to be an effective problem solver, and to 
communicate, to network and to lead. Entrepreneurship is not necessarily a topic - it is also a different way of teaching and of helping young people to fully develop their potential (European Commission, 2012).

For Izedonmi and Okafor (2010), entrepreneurial education is focused on developing youth with the passion and multiple skills, and aims to reduce the risks associated with entrepreneurial thought. For Drucker (2001) this type of education has been identified as the engine for economic development and employment creation and is assumed to be a crucial factor for developing the entrepreneurial potential among young population (Nikoloski, Angeleski, Rocheska, \& Mancheski, 2014). The latter authors say that, while it is recognized that individual characteristics, traits and/or contextual factors may play dominant role in the entrepreneurial propensity of a given person, it is still questionable whether it is possible for people to learn to be entrepreneurs. Despite this comment, the crucial role in developing enterprising tendency and shaping the entrepreneurial characteristics of students on all levels of education is played by entrepreneurship education (Holienka, Holienková, \& Gál, 2015). Moreover, there is a lack of studies regarding entrepreneurial intention or propensity of Brazilian students, despite the growth of entrepreneurship programs as shown above.

Within this context, it is important to analyze the potential contribution of higher education on students' entrepreneurial intentions. Therefore, the objective of this paper is to examine the impact of the exposure to entrepreneurship education on students' entrepreneurial intentions.

Emphasis is placed on the understanding of the students' entrepreneurial behavior because they are individuals exposed to entrepreneurship education and the role of the educational institution is to provide this education and to foster entrepreneurial behavior among them. In order to examine the entrepreneurial intention, we applied a questionnaire based on McClelland model on a sample of 230 Business undergraduate students of a Brazilian university.

\section{Literature Review}

\subsection{Entrepreneurship Education in Higher Education}

Many studies are devoted on understanding the effect or role of entrepreneurship education on students' entrepreneurial intentions or fostering their potential. Alvarez, de Noble and Jung (2006) argue that universities should emphasize and provide entrepreneurship education and that, when presented to students, their intentions and self-efficacy were positively influenced. For Iglesias-Sanchez, Jambrino-Maldonado, Velasco and Kokash (2016), the students' predisposition from Malaga University to entrepreneurship is moderate because perceived risk and their own abilities hinder their decision to start up a business.

In Nikoloski et al. study (2014), they assessed the role of higher education in two universities, Albania and Macedonia, in fostering the students' entrepreneurial potential and found that only a small portion of them attempted to develop their business ideas in practice. Izedonmi and Okafor (2010) revealed that Nigerian students' exposure to entrepreneurship education has a positive influence on their intentions. They concluded that although participating in entrepreneurial education may not necessarily lead to entrepreneurial intentions; it has a way of motivating students in initiating entrepreneurial venture. This finding is similar to Oguntimehin and Olaniran (2017) where entrepreneurship education significantly influences students' entrepreneurial intentions.

Pacheco and Moretto Neto (2007) investigated the contribution of a Business undergraduate course to the entrepreneurial development of the class 2005 students and found that the majority of disciplines did not present satisfactory rates regarding the entrepreneurial formation. Spiteri and Maringe (2014) identified four essential components that reflect the nature of entrepreneurial education in universities in Europe: pedagogy; content; assessment; and role model lecturer. In a similar study, satisfaction of university students in Indonesia was investigated in terms of learning and teaching contents, teaching methods and expected outcomes with the implementation of entrepreneurship education (Abduh, Maritz, \& Rushworth, 2012). Results identified an overall satisfaction with entrepreneurship education with opportunities in areas of pedagogy and learning contents, and resources.

Vukovic, Kedmenec and Korent (2015) present four different concepts or levels of entrepreneurship education: entrepreneurial awareness education; education for start-up; entrepreneurial dynamism education; and continuing education for entrepreneurs.

The studies presented above and discussed in this paper refer to awareness education aiming to increase the number of people with insights into small business, self-employment and entrepreneurship.

\subsection{Models of Enterprising Tendency Based on Personality Traits and/or Characteristics}

The following studies discuss some measures and models of enterprising tendency based on personality traits and/or characteristics. The first one is the General Measure of Enterprising Tendency (GET) test developed in 1987-1988 by Dr Sally Caird and Mr Cliff Johnson at Durham University Business School (please see http://www.get2test.net/get2test.html). The research followed a literature review to identify key psychological 
characteristics of entrepreneurs, which could be applicable to other enterprising people. Psychological tests were reviewed and a bank of entrepreneurial descriptive statements was assembled from the literature on entrepreneurs, the psychological tests of key entrepreneurial characteristics, and pilot testing with entrepreneurs. The key entrepreneurial characteristics identified were: strong motivation, characterized by a high need for achievement and for autonomy; creative tendency; calculated risk-taking; and an internal locus of control (belief you have control over own destiny and make your own 'luck'). People set up an enterprise because they are highly motivated (to achieve something themselves) by a good idea and will manage risks, information and uncertainties (Caird, 1991).

These characteristics were the same used in Holienka et al. study (2015) in a sample of 170 students from four different fields of study: business administration; applied informatics; psychology; and pedagogy. They found that business administration students exhibited significant differences from all other fields in the overall enterprising tendency, as well as in case of need for achievement and calculated risk-taking.

A conceptual model to assess entrepreneur's personality characteristics and success was proposed by Rauch and Frese (2012). They assumed that broad personality traits influence specific personality traits that, in turn, influence goals and action strategies that will result in business creation and success. Some of their specific personality traits are similar to those presented by Caird, that are: need for achievement; risk taking; innovativeness; autonomy; locus of control; and self-efficiency.

In another study, six personality characteristics were used to define the entrepreneurial profile of Turkish university students: need for achievement; locus of control; risk taking propensity; tolerance for ambiguity; innovativeness; and self-confidence (Gurol \& Atsan, 2006). They found out that there are significant differences between entrepreneurially inclined students and those who are not inclined with regard to need for achievement, locus of control, risk taking propensity, and innovativeness.

Another model presented was devised by David McClelland. He was one of the first to use behavioral science theories to study the motivations to undertake (Oliveira, 2010). At the request of USAID United States Agency for International Development, he designed a study that aimed to identify the entrepreneurial behavior characteristics in emergent countries. After four years of research, in 1987, the final report of this project was published together with a questionnaire that would be able to measure the entrepreneurial behavior characteristics (Mansfield, McClelland, Spencer, \& Santiago, 1987). After few years, at request of United Nations Conference on Trade and Development (UNCTAD), Harvard University, in partnership with David McClelland, developed the methodology of the EMPRETEC program based on his study (UNCTAD, 2010). In this model, there are three main constructs: i) Need for achievement; ii) Need for Planning and iii) Need for Power. Below them there are ten characteristics named Personal Entrepreneurial Competencies (PECs) used as assessment of strengths and weaknesses of entrepreneurship (please see figure 1). The final questionnaire consisted of 55 statements - five to each of ten characteristics - and five remaining statements that were part of a correction factor created with control objective in case the respondent attempted to pass a better image of himself in the answers. Each statement has a likert scale of five points of how much the respondent agreed with it $(1=$ never..., 5 = always) (Mansfield et al, 1987). Therefore, each characteristic ranges from 5 to 25 points, McClelland considers that from 15 points onwards, the respondent presents tendency to undertake, The questionnaire can be found in Paletta (2001).

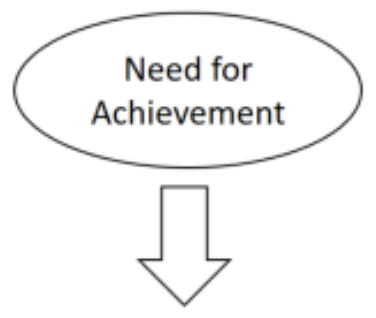

FC - Fulfilling commitments

DQE - Demand for quality and efficiency

PER - Persistence

TCR - Taking calculated risks

OSI - Opportunity-seeking and initiative

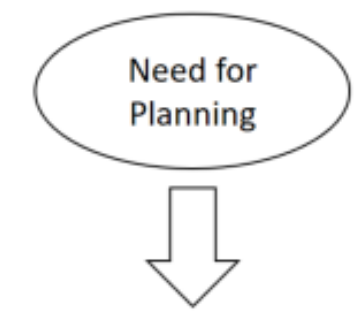

GS - Goal-seeking

IS - Information-seeking

SPM - Systematic planning

and monitoring

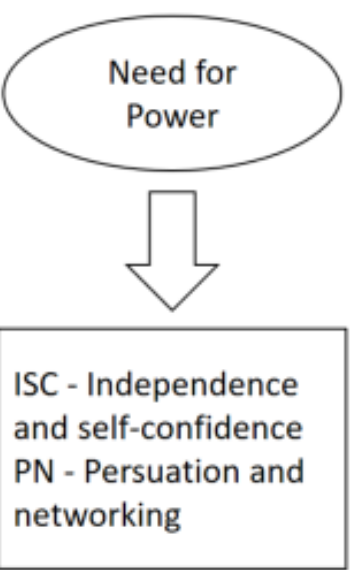

ISC - Independence and self-confidence networking

Figure 1. McClelland model for EMPRETEC (Source: UNCTAD, 2010)

McClelland model was used to assess the entrepreneurial characteristics of a group of Brazilian pharmacists (Câmara \& 
Andalécio, 2012), of a group of Brazilian students (Ching \& Kitahara, 2015) and a comparison of the differences in the entrepreneurial profile between researchers, entrepreneurs and students in Philippines (Depositário, Aquino, \& Feliciano, 2011).

\section{Research Method}

This is an exploratory quantitative study aimed at examining the impact of the exposure to entrepreneurship education on students' entrepreneurial intentions. The study utilized the case study approach in a higher education institution located in the region of São Paulo city, in Brazil.

The sample of the study comprised of 230 undergraduate students of the Business course throughout a period of eight semesters, from 2014 to 2017, representing more than 50\% of the total sample. In each semester, a different group of students responded the questionnaire, all of them in the same semester of the course. The data collection tool for this research was a questionnaire sent to be filled on line by the students.

Students from this Brazilian university are exposed to a "hands on" form, conceiving the idea into opportunity, preparing a business plan and turning the project into a MVP Minimum Viable Product.

To examine the impact of the exposure to entrepreneurship education on students' entrepreneurial intentions, some statistical tools described hereinafter were used (t-Student test, ANOVA, Hierarchical Cluster, K-Means Cluster, Cross tabulation, Chi-Square test) (Hair, Anderson, Tatham, \& Black, 2005; Fávero, Belfiore, Silva, \& Chan, 2009). The research plan strategy was developed to find answers using multiples comparisons techniques.

Some characteristics that differentiate individuals were measured using t-Student Test for Dichotomous Variables and One Way ANOVA for multilevel qualitative variables. If rational common-sense points that would have differences and did not happen in the sample, it is supposed that effects due the education are stronger than natural differentiation factors (personal characteristics, environment, social/ political/ economical influence).

In applying analysis in transversal (over the full sample) and longitudinal (each semester) approach, we believe that conclusions can take place without use of control group as comparison technique. Also, analyzing phenomena over time and not finding significant changes, where it is supposed to happen due normal volatility, points those long-term objectives in learning methods and contents (entrepreneurship) drive behavior damping that volatility.

Another study is to identify characteristic groups inside the population (segmentation) and we use Cluster Analysis. Since K-Means Cluster Analysis depends on researcher decision to define the amount of groups' definition. Cluster Analysis starting with Hierarchical Clustering provides good suggestion to establish a suitable amount of clusters to represent the segmentation of sample cases (Fávero et al., 2009). K-Means Cluster Analysis for segmentation is suitable in our case since data structure it is not hierarchical.

To improve the resolution of measurements, we changed the scale of original 5 points Likert scale in McClelland questionnaire to a scale from 0 to 10 (since decimal scale is well developed by humans as evaluation measuring standard), but adjusted value zero in responses set to 1 in order to maintain McClelland scale proportionality the same. Thus, full scale means 50 instead of 25 and threshold of 30 instead of 15 as McClelland defines as intention to undertake. Processing tool used in calculations was SPSS version 19.

\section{Analysis of the Results and Discussion}

Descriptive perception based on mean of each PEC factor is presented in table 1 . Value mostly above 30 indicates intention to undertake as already mentioned.

Table 1. Mean of PEC factors

\begin{tabular}{cccccccccc}
\hline Mean & Overall & 1 S2014 & 2 S2014 & 1S2015 & 2S2015 & 1S2016 & 2S2016 & 1S2017 & 2S2017 \\
\hline OSI & 34.83 & 33.98 & 33.53 & 36.00 & 34.28 & 35.66 & 36.69 & 35.57 & 34.00 \\
PER & 32.60 & 32.40 & 32.34 & 33.18 & 31.44 & 32.06 & 33.88 & 33.39 & 32.54 \\
FC & 37.55 & 37.51 & 36.94 & 37.50 & 38.28 & 37.89 & 37.56 & 37.46 & 37.58 \\
DQE & 35.82 & 36.55 & 35.28 & 35.36 & 35.78 & 35.83 & 37.50 & 36.11 & 34.35 \\
TCR & 30.41 & 29.72 & 30.28 & 32.00 & 29.33 & 29.97 & 30.38 & 32.39 & 29.35 \\
GS & 38.83 & 38.49 & 38.22 & 39.54 & 36.33 & 39.43 & 40.81 & 40.00 & 37.85 \\
IS & 36.95 & 34.68 & 35.28 & 38.46 & 37.00 & 38.40 & 38.88 & 38.43 & 36.73 \\
SPM & 34.25 & 33.28 & 31.94 & 35.39 & 32.00 & 34.94 & 37.50 & 36.43 & 33.88 \\
PN & 32.63 & 31.49 & 31.56 & 32.75 & 31.61 & 34.51 & 34.31 & 33.86 & 31.65 \\
ISC & 35.48 & 33.98 & 35.09 & 37.04 & 35.22 & 36.51 & 35.13 & 37.54 & 33.77 \\
\hline Sample size & 230 & 47 & 32 & 28 & 18 & 35 & 16 & 28 & 26 \\
\hline
\end{tabular}

We started investigating whether i) the student's gender; ii) student or student's family has own business and; iii) prior experience in the family business influences his (her) entrepreneurial intention. 
Following, we proceeded to a longitudinal analysis, verifying whether the behavior characteristics reflecting the entrepreneurial intentions of the students changed over eight semesters $(2014-2017)$.

The third and last test was to check whether students would be segmented in different groups of entrepreneurial behavior reflecting their intention to undertake.

For the first test, the results of t-Student test presented in table 2 indicate that there are no evidences that any of these three factors have some influence to discriminate entrepreneurial intention, based on their responses with level of confidence of $95 \%$. Since SIG, the value of the probability, is higher than $5 \%$ or 0.05 (the level of significance defined in the research planning), the above statement is confirmed.

Table 2. T-Student Test for discriminant factors (Level of Confidence $=95 \%$ )

\begin{tabular}{cccc}
\hline & \multicolumn{3}{c}{ Hypothesis Test [SIG = P(t-Student value of sample)] } \\
\hline PCE fator & Student's Gender? & $\begin{array}{c}\text { Student's family has } \\
\text { own business? }\end{array}$ & $\begin{array}{c}\text { Student's prior experience in the } \\
\text { family business? }\end{array}$ \\
\hline OSI & .635 & .927 & .751 \\
PER & .379 & .863 & .368 \\
FC & .698 & .707 & .935 \\
DQE & .787 & .444 & .731 \\
TCR & .422 & .937 & .189 \\
GS & .806 & .256 & .216 \\
IS & .524 & .206 & .055 \\
SPM & .260 & .536 & .309 \\
PN & .058 & .775 & .498 \\
ISC & .055 & .932 & .942 \\
\hline Quantity of & Female $=133$ & No $=151$ & No $=166$ \\
responses & Male $=97$ & Yes $=79$ & Yes $=64$ \\
\hline
\end{tabular}

Oguntimehin and Olaniran study (2017) showed there was no significant difference in the entrepreneurial intentions of male and female students as well as on their age group in Nigerian undergrad students. To contrast with these findings, Palalic, Ramadani, Dilovic, Dizdarevic and Ratten (2017) found that students with prior entrepreneurial experience scored higher in both the entrepreneurial desire and orientation than students without experience. The same happens with the gender where males have higher entrepreneurial desire and orientation. Among the entrepreneurially inclined students, 53\% had parents occupied with independent business against $19 \%$ with no inclination.

We used ANOVA test to identify whether the behavior characteristics reflecting the entrepreneurial intentions of the students changed over eight continuous semesters and the results are in table 3. Since SIG is higher than 5\% or 0,05, except for SPM factor, we confirm that there are no significant differences among the mean values of each factor of the eight semesters. With confidence level of 95\%, this does not mean that they, except SPM, are the same, but the differences do not point to significant changes. For SPM, ANOVA shows that there is at least one semester different from the remaining seven.

Table 3. ANOVA test of longitudinal analysis (1st S2014 - 2nd S2017)

\begin{tabular}{lcc}
\hline \multicolumn{1}{c}{ PCE factor } & F value & Sig, \\
\hline OSI - Opportunity-seeking and initiative & .845 & .551 \\
PER - Persistence & .363 & .923 \\
FC - Fulfilling commitments & .099 & .998 \\
DQE - Demand for quality and efficiency & .405 & .898 \\
TCR - Taking calculated risks & .931 & .483 \\
GS - Goal-seeking & .821 & .570 \\
IS - Information-seeking & 1.994 & .057 \\
SPM - Systematic planning and monitoring & 2.257 & .031 \\
PN - Persuasion and networking & 1.385 & .213 \\
ISC - Independence and self-confidence & 1.267 & .268 \\
\hline
\end{tabular}

In order to analyze qualitatively the behavior of SPM factor, Figure 2 presents Box-plots along the period of eight semesters, where 30 is the adjusted threshold value suggested by McClelland for intention to undertake. We can note that differences are not so wide between the semesters to justify that they are different from each other at level of confidence of $95 \%$ (yellow box limits $1^{\text {st }}$ and $3^{\text {rd }}$ quarter/quartile $=50 \%$, then, about $75 \%$ or more are above this limit). 


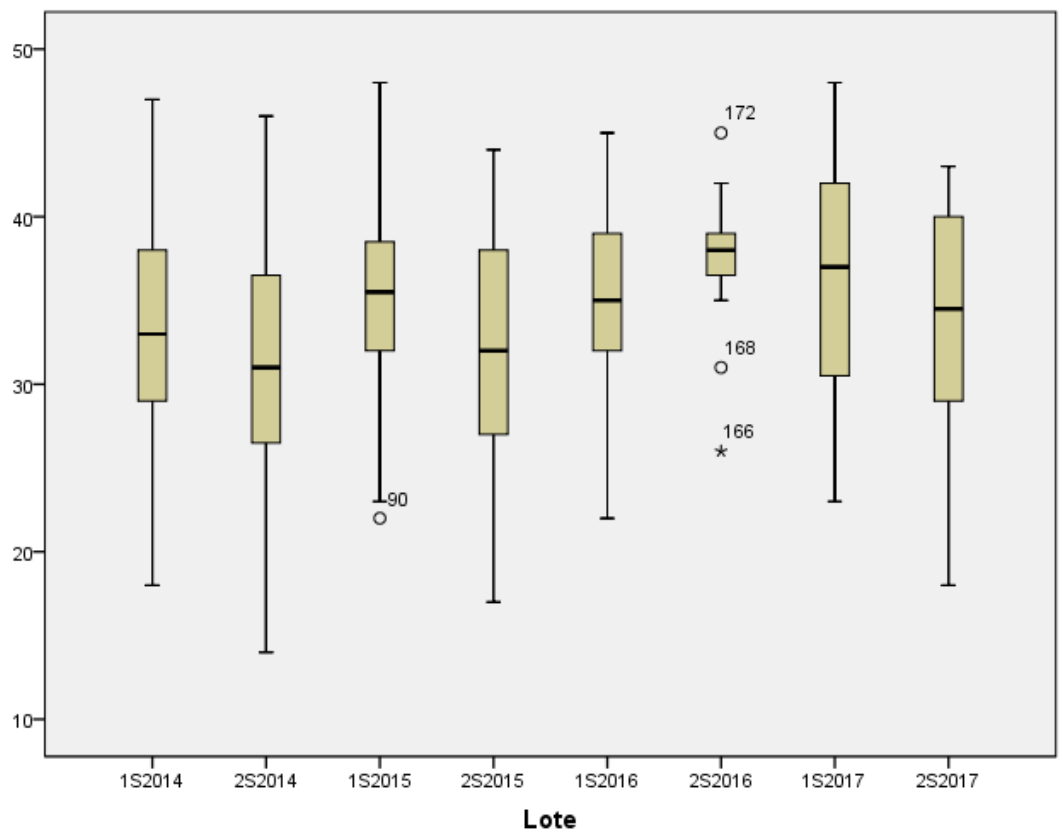

Figure 2. Box-plot of SPM factor

We can speculate that the above students' pattern is comparable over the period of eight semesters because they have similar socioeconomic and educational profiles, and a supposed homogenous "mental model" for entrepreneurship as result of the activities and concepts presented in the course.

In order to evaluate the level of intention to undertake measured by mean of each PCE factor, we have used Hierarchical Cluster Analysis to establish a suitable amount of clusters to represent that segmentation. When observing the Dendogram generated, it was clear that there are two different groups. Table 4 presents the results of K-Means Cluster Analysis settled in two groups. The ANOVA test indicates that all PEC factors contributed to the formation of two groups with confidence level of $95 \%$. Group 1 refers to the students (135 responses) with more intention to undertake and with higher absolute values for PEC mean (average) (between 33,7 and 42,8) while Group 2 represents the opposite, with less intention with absolute values between 25,8 and 33. Nevertheless, the students of this Group 2 ( 95 responses) have mean values around 30, considered by McClelland (1961) as the minimum value and we can assign lesser intention to undertake.

Table 4. K-Means Cluster Analysis Result

\begin{tabular}{|c|c|c|c|c|}
\hline \multirow{2}{*}{ PEC factor } & \multicolumn{2}{|c|}{ Mean (Average) } & \multicolumn{2}{|c|}{ ANOVA Test } \\
\hline & Group 1 & Group 2 & F value & Sig \\
\hline OSI - Opportunity-seeking and initiative & 37.9 & 30.5 & 108.570 & .000 \\
\hline PER - Persistence & 35.9 & 27.9 & 174.583 & .000 \\
\hline FC - Fulfilling commitments & 40.8 & 33.0 & 159.462 & .000 \\
\hline DQE - Demand for quality and efficiency & 39.3 & 30.9 & 118.278 & .000 \\
\hline TCR - Taking calculated risks & 33.7 & 25.8 & 140.943 & .000 \\
\hline GS - Goal-seeking & 42.8 & 33.1 & 202.137 & .000 \\
\hline IS - Information-seeking & 39.8 & 32.9 & 82.972 & .000 \\
\hline SPM - Systematic planning and monitoring & 37.7 & 29.4 & 139.539 & .000 \\
\hline PN - Persuasion and networking & 35.3 & 28.9 & 84.312 & .000 \\
\hline ISC - Independence and self-confidence & 38.4 & 31.3 & 79.200 & .000 \\
\hline
\end{tabular}

A possible explanation of the above results is that the students of this Brazilian university are exposed to an experiential learning form or a "hands on" form. This means engaging and involving them in activities and assignments that contribute to the development of their competencies, conception of idea into opportunity, preparation of business plan with the aid of mentors and finishing with a pitch presentation to a group of investors analyzing the students' MVP Minimum Viable Product. While the business plan model provides the students with a specific project oriented output, they can gather experience from the past and modify the quality of proceeding experiences. Gorman (1997) states that entrepreneurial propensity can be enriched with active experimentation, concrete experience and abstract conceptualization.

The more predominant five characteristics in Group 1 are: Goal-seeking; fulfilling commitments; Information seeking; Demand for quality and efficiency; and Independence and self-confidence. These characteristics are the same in Group 2. The lowest score in both groups is for taking calculated risks. 
In Camara and Andalécio (2012) study, the highest scores were in the characteristics Opportunity-seeking and Initiative, and Fulfilling Commitments while the lowest scores were in Persuasion and Networking, and Demand for Quality and Efficiency, Goal-seeking and Fulfilling Commitments are the highest scores while Taking Calculated Risks and Persuasion and Networking are the lowest scores in Ching and Kitahara's study (2015).

Finally, we compared whether the level of intention to undertake (high, medium or low), as this was one of the questions in the questionnaire, is correlated with the two groups found in K-Means Cluster Analysis (table 4). This is presented in table 5 with Cross tabulation and Chi-Square tested as discrimination factor for PCE factors. Cross tabulation quantifies responses based on personal opinion of three level intentions to undertake (high, medium or low) versus latent perception K-Means Cluster analysis found by McClelland PCE factors. Since Sig equals 0,936, higher than level of significance of $5 \%(0,05)$, there is no relationship between those two variables. This mean that in both groups we found potential people that will indistinctly become employee (less intention to undertake) or self-employee (more intention to undertake).

Table 5. Relationship between intentions to undertake opinion versus K-Means groups

\begin{tabular}{|c|c|c|c|c|c|c|}
\hline \multicolumn{3}{|c|}{ Questionnaire: Intention to have your own business } & Low & Medium & High & Total \\
\hline \multirow{2}{*}{ Cluster Number of Case } & Group 1 & $\begin{array}{l}\text { Count } \\
\text { Expected Count }\end{array}$ & $\begin{array}{c}26 \\
27.0\end{array}$ & $\begin{array}{c}48 \\
47.9\end{array}$ & $\begin{array}{c}66 \\
65.1\end{array}$ & $\begin{array}{c}140 \\
140.0\end{array}$ \\
\hline & Group 2 & $\begin{array}{l}\text { Count } \\
\text { Expected Count }\end{array}$ & $\begin{array}{c}18 \\
17.0\end{array}$ & $\begin{array}{c}30 \\
30.1\end{array}$ & $\begin{array}{c}40 \\
40.9\end{array}$ & $\begin{array}{c}88 \\
88.0\end{array}$ \\
\hline Total & & $\begin{array}{l}\text { Count } \\
\text { Expected Count }\end{array}$ & $\begin{array}{c}44 \\
44,0\end{array}$ & $\begin{array}{c}78 \\
78.0\end{array}$ & $\begin{array}{c}106 \\
106.0\end{array}$ & $\begin{array}{c}228 \\
228.0\end{array}$ \\
\hline
\end{tabular}

\begin{tabular}{lcc}
\hline \multicolumn{1}{c}{ Chi-Square Test } & Value & Sig \\
\hline Pearson Chi-Square & .133 & .936 \\
N of Valid Cases & 228 & \\
\hline
\end{tabular}

\section{Conclusions}

Based on personal opinion regarding McClelland questionnaire responses, no differences were significant to discriminate gender, nor previous experiences on family business (existence of family business and live experiences in it). Yet, there were no significant changes of PEC factors mean values when considering longitudinal behavior in units of semesters in the period of 2014 to 2017.

We risk considering that common factors should be in place that hold the variability to stay within confidence level of $95 \%$, meaning that there are not significant differences in those comparisons. One of those intervenient factors would be the content of the course that represents concepts and tasks aimed to develop entrepreneurship approach.

Although there are two groups representing different levels of intention to undertake, even the group with less intention (Group 2) presents mean value around and/or above the minimum threshold value (as 30) mentioned by McClelland. The results of all tests provide empirical evidences that allow us to confirm our objective, that the exposure to entrepreneurial education influences positively the students' entrepreneurial intentions.

Moreover, table 5 results bring the scenario of four possibilities: i) potential self-employee working as self-employee; ii) potential self-employee working as employee; iii) potential employee working as self-employee; and iv) potential employee working as employee. Sample data shows no bias on career decision at this stage of the course.

Although we have focused in this paper in university education, the entrepreneurial education may not be only related to development of entrepreneurs or tied to the specifics of starting a business. Yet, it should also contribute to economic development, enterprising spirit and work skills among people aiming professional self-realization in various contexts. This position is shared by IAC (2006) and Caird (1990). Gurol and Atsan (2006) state that higher education should be seeking to nurture and develop the entrepreneurial characteristics in all students. We agree with Holienka et al. (2015) that development of entrepreneurial characteristics is important in all fields of study and entrepreneurship education is key to face the challenges of current economic context. This is in line with Iglesias-Sanchez et al. (2016) that entrepreneurship should be a cross-curricular competence of any university qualification.

Nevertheless, the effectiveness and impact of entrepreneurship education is still an open issue because most students do not start new ventures right after finishing their higher education. This makes it difficult to observe and precisely measure any causal relationship (Souitaris, Zerbinati, \& Al-Laham, 2007), Therefore, the impact on student' entrepreneurial characteristics, their intention to undertake and/or changes in entrepreneurial intention rates are more often used to measure the outcomes of entrepreneurial education.

Having in mind the previous findings, we suggest some directions for policy intervention in the area of the higher education in Brazil: i) entrepreneurship becomes an interdisciplinary program and be present in all courses; ii) adoption 
of prizes and contests that will create incentives for generating interesting projects by the students; iii) bring universities closer to the market by strengthening the entrepreneur ecosystem formed by business incubators, innovation centers and business angels to turn the projects into successful start-ups and; iv) create mentoring program to share experience and counsels. On top of these directions, policies for the development of entrepreneurship should be designed and implemented by the government to increase the students' entrepreneurial desires.

In the learning process of students, teaching pedagogy is essential. As stated by Spiteri and Maringe (2014) and Oguntimehin and Olaniran (2017), it should focus on learning by doing and be practical oriented and the lecturers should adopt innovative approaches that engage students in activities that enhance entrepreneurial learning and motivation.

Because this is an exploratory study, focusing on the students' entrepreneurial characteristics, it is not possible to measure whether the level of entrepreneurship education has resulted in self-employment and this is a limitation of the study. Suggestion for future study is to perform a similar study with students of other fields of study and compare the results.

\section{References}

Abduh, M., Maritz, A., \& Rushworth, S. (2012). An evaluation of entrepreneurship education in Indonesia: a case study of Bengkulu University. The International Journal of Organizational Innovation, 4(4), 21-47.

Alvarez, R., de Noble, A., \& Jung, D. (2006). Educational Curricula and Self-Efficacy: Entrepreneurial Orientation and New Venture Intentions among University Students in Mexico, in Craig, S., Galbraith, C., \& Stiles, H. (ed.) Developmental Entrepreneurship: Adversity. Risk and Isolation (International Research in the Business Disciplines, 5, Emerald Group Publishing Limited. 379 - 403.

Caird, S. (1990). What does it mean to be enterprising? British Journal of Management, 1(3), 117-145. https://doi.org/10.1111/j.1467-8551.1990.tb00002.x.

Caird, S. (1991). Testing enterprising tendency in occupational groups. British Journal of Management, 2(4), 177-186. https://doi.org/10.1111/j.1467-8551.1991.tb00025.x.

Camara, E. C., \& Andalécio, A. M. L. (2012). Características empreendedoras: um estudo de caso com farmacêuticos utilizando o modelo de McClelland. Revista de Empreendedorismo e Gestão de Pequenas Empresas, 1(3), 64-77. https://doi.org/10.14211/regepe.v1i3.32

Ching, H. Y., \& Kitahara, J. R. (2015). Propensão a empreender: uma investigação quantitativa baseada nas características empreendedoras de alunos do curso de Administração. Revista de Ciências da Administração, 17(43), 99-111. https://doi.org/10.5007/2175-8077.2015v17n43p99.

Depositário, D., Aquino, N., \& Feliciano, K. (2011). Entrepreneurial skill development needs of potential agri-based technopreneurs. ISSAAS Journal, 1, 106-120.

Drucker, F. P. (2001). Innovation and Entrepreneurship. Butterworth-Heinemann. Oxford.

Endeavor \& Sebrae. (2015). Empreendedorismo nas universidades brasileiras 2014. Retrieved from https://d335luupugsy2.cloudfront.net/cms\%2Ffiles\%2F6588\%2F14259446422014+-+Universidades+-+Principal+ quantitativo.pdf

Endeavor \& Sebrae. (2017). Empreendedorismo nas universidades brasileiras 2016. Retrieved from https://d335luupugsy2.cloudfront.net/cms\%2Ffiles\%2F6588\%2F1476473621Relatorio+Endeavor+digital+\%283\% 29.pdf

European Commission. (2012). Effects and impact of entrepreneurship programmes in higher education. Entrepreneurship Unit, Directorate General for Enterprise and Industry.

Fávero, L. P., Belfiore, P., Silva, F. L., \& Chan, B. L. (2009). Análise de dados: modelagem multivariada para tomada de decisões. Rio de Janeiro: Elsevier.

GEM Global Entrepreneurship Monitor. (2015). Empreendedorismo no Brasil, Relatório Executivo.

Gorman, G. (1997). Some research perspectives on entrepreneurial education enterprise education and education for small business management: a ten-year literature review. International Small Business Journal, 15(3), 56-79. https://doi.org/10.1177/0266242697153004.

Gurol, Y., \& Atsan, N. (2006). Entrepreneurial characteristics amongst university students. Education + Training, 48(1), 25-38. https://doi.org/10.1108/00400910610645716

Hair, J. J. F., Anderson, R. E., Tatham, R. L., \& Black, W. C. (2005). Análise Multivariada de Dados. $5^{\mathrm{a}}$ ed. Tradução Adonai Schlup e Anselmo Chaves Neto. Porto Alegre: Bookman. 
Holienka, M., Holienková, J., \& Gál, P. (2015). Entrepreneurial characteristics of students in different fields of study: a view from entrepreneurship education perspective. Acta Universitatis Agriculture et Silvicuturae Mendelianae Brunensis, 63(6), 1879-1889. https://doi.org/10.11118/actaun201563061879

IAC Integral Assets Consulting. (2006). Youth Entrepreneurship: Theory. Practice and Field Development. A Background Paper Prepared for the W. K. Kellogg Foundation Youth and Education Unit.

Iglesias, S. P. P., Jambrino, M. C., Velsco, A. P., \& Kokash, H. (2016). Impact of entrepreneurship programmes on university students. Education + Training, 58(2), 209-228. https://doi.org/10.1108/ET-01-2015-0004

Izedonmi, P. F., \& Okafir, C. (2010). The effect of entrepreneurship education on students' entrepreneurial intentions. Global Journal of Management and Business Research, 10(6), 49-60.

Mansfield, R. S., McClelland, D. C., Spencer, J. L. M., \& Santiago, J. (1987). The identification and assessment of competencies and other personal characteristics of entrepreneurs in developing countries. Boston. Massachusetts. United States: McBer and Company.

McClelland, D. (1961). The Achieving Society. Princeton: D. Van Nostrand CO. https://doi.org/10.1037/14359-000

Nikoloski, D., Angeleski, M., Rocheska, S., \& Mancheski, G. (2014). Does the higher education promote students' entrepreneurial potential in the South-Eastern European countries? Annuals of the Constantin Brâncusi University of Târgu Jiu. Economy Series, 2, 6-12.

Oguntimehin, Y. A., \& Olaniran, O. O. (2017). The relationship between entrepreneurship education and students'entrepreneurial intentions in Ogun State-owned universities, Nigeria. British Journal of Education, 5(3), 9-20.

Oliveira, J. M. (2010). Lócus de controle e a efetividade empresarial em microempresários do Estado do Rio Grande do Norte. Master's thesis. Universidade Federal do Rio Grande do Norte. Natal.

Pacheco, A. S. V., \& Moretto, N. L. (2007). A contribuição do curso de administração da universidade federal de Santa Catarina para o desenvolvimento de competências empreendedoras. Revista de Ciências da Administração, 9(17), $1-24$.

Palalic, R., Ramadani, V., Dilovic, A., Dizdarevic, A., \& Ratten, V. (2017). Entrepreneurial intentions of university students: a case-based study. Journal of Enterprising Communities: People and Places in the Global Economy, 11(3), 393-413. https://doi.org/10.1108/JEC-12-2016-0046

Paletta, M. A. (2001). Vamos abrir uma pequena empresa: um guia prático para abertura de novos negócios. Campinas. SP: Alinea.

Rauch, A., \& Frese, M. (2012). Born to be an entrepreneur? Revisiting the personality approach to entrepreneurship. In: Baum, J. R. et al. (eds.). The Psychology of Entrepreneurship. New York. NY: Psychology Press.

Souitaris, V., Zerbinati, S., \& Al-Laham, A. (2007). Do entrepreneurship programmes raise entrepreneurial intention of science and engineering students? The effect of learning, inspiration and resources. Journal of Business Venturing, 22(4), 566-591. https://doi.org/10.1016/j.jbusvent.2006.05.002

Spiteri, S., \& Maringe, F. (2014). EU entrepreneurial learning: perspectives of university students. Journal of Enterprising Communities: People and Places in the Global Economy, 8(1), 51-70. https://doi.org/10.1108/JEC-07-2013-0023

UNCTAD EMPRETEC Programme. (2010). The Entrepreneur's Guide. Geneva. Switzerland.

Vieira, S. F. A., Melatti, G. A., Oguido, W. S., Pelisson, C., \& de Negreiros, L. F. (2013). Ensino de Empreendedorismo em cursos de Administração: um levantamento da realidade brasileira. R. Adm. FACES Journal Belo Horizonte, 12(2), 93-114.

Vukovic, K., Kedmenec, I., \& Korent, D. (2015). The Impact of exposure to entrepreneurship education on student entrepreneurial intentions. Croatian Journal of Education, 17(4), 1009-1036.

\section{Copyrights}

Copyright for this article is retained by the author(s), with first publication rights granted to the journal.

This is an open-access article distributed under the terms and conditions of the Creative Commons Attribution license which permits unrestricted use, distribution, and reproduction in any medium, provided the original work is properly cited. 